\title{
Experimental study of brick masonry walls strengthened with textile reinforced mortar
}

\author{
BERNAT, Ernest ${ }^{1}$, GIL, Lluis ${ }^{2}$ and ROCA, Pere ${ }^{3^{*}}$ \\ ${ }^{1}$ Universitat Politècnica de Catalunya, Colom 1, 08222 Terrassa, Spain \\ ${ }^{2}$ Universitat Politècnica de Catalunya, Colom 1, 08222 Terrassa, Spain \\ ${ }^{3}$ Universitat Politècnica de Catalunya, Jordi Girona 1-3, 08034 Barcelona, Spain \\ 1ernest.bernat@upc.edu, ${ }^{2}$ lluis.gil@upc.edu, ${ }^{3}$ pere.roca.fabregat@upc.edu
}

Keywords: Brick masonry walls, textile reinforced mortar (TRM), bucking failure

\begin{abstract}
The paper presents an experimental research on the use of Textile Reinforced Mortar (TRM) for the strengthening of brick load bearing masonry walls subjected to eccentric loading. Particular attention is given to the case of slender walls and to the ability of TRM reinforcement to enhance the response of such walls against buckling failure. The research has allowed the study of the influence of different mortar and fibre grid types and the possible benefit of using anchors to improve the connection between the walls and the external reinforcement. The experimental campaign has consisted of twelve tests on full scale wall specimens using a specific testing device designed to create a hinged boundary condition at the top and bottom wall ends. It has been observed that TRM reinforcement provides a significant increase of over $100 \%$ of the initial load bearing capacity under eccentric axial load. Moreover, a stiffer and more homogeneous behavior is noticed when TRM is applied. A simplified analytical method to calculate the ultimate axialbending combination for TRM strengthened brick masonry walls, in agreement with the experiments, is also presented.
\end{abstract}

\section{Introduction}

In many countries, load bearing masonry buildings are still the most abundant type of structures in use for residential or other purposes. Conservation and upgrading of these buildings requires efficient and sustainable solutions for consolidation and strengthening. In many cases, strengthening is needed because of the higher load capacity demanded by new uses. The structural verification or the upgrading to new load levels requires, in particular, a detailed study of the capacity of the unstrengthened or strengthened walls taking into consideration second order equilibrium effects and the possibility of a buckling failure. While this type of verification is needed for all type of walls, it becomes especially critical in the case of slender walls or walls subjected to significant load eccentricity.

Aiming to investigate adequate solutions for the strengthening of slender masonry walls, a research is herein presented on the use of Textile Reinforced Mortar (TRM) as a way to mitigate second order effects and increase the load bearing capacity of brick masonry walls. The proposed solutions aim to provide a sustainable and affordable technology for the strengthening of load bearing wall buildings. The solution can be considered satisfactorily non-invasive and removable thanks to the use of lime based or Portland cement based mortars instead of epoxy ones.

Retrofitting systems based on TRM have been recently presented for the strengthening of masonry walls against, especially against seismic in-plane and out-of-plane shear forces [1-6]; however, the performance of TRM reinforcement against buckling failure and out-of-plane second order effects has not yet been widely investigated.

The research presented has included the study of the influence of several parameters on the efficiency of TRM as a solution for the reinforcement of load bearing brick walls subjected to vertical loading. Specifically, the influence of the amount of fibers, their nature (glass or carbon 
fibers) and the type of binding mortar (Portland-, lime- or pozzolana-based ones) on the behavior of the strengthened walls have been analyzed by testing twelve walls with different reinforcement arrangements. All walls have been tested in a hinged-hinged configuration, with the same load eccentricity at both ends.

A simplified method based on equilibrium and strain compatibility equations is proposed. It is assumed that the walls fail when the stresses reach the strength of any of the component materials. In addition, it is supposed that the strengthening system prevents the pure buckling failure and limits second order effects.

\section{Experimental research}

The experimental works included the study of the influence of different variables on the load bearing capacity of the strengthened walls. These variables comprised the type of fibre grids, the number of grids installed, the type of mortar and the possible use of connectors between the TRM and the wall. Regarding the type of fibres, both glass and carbon ones were investigated. These were combined with three different mortar types based respectively on Portland cement, lime and pozzolana. The properties of the mortars and fibers are summarized in tables 1 and 2 . The fibre grid properties were provided by the manufacturer whereas the mortar properties (compressive and flexural strength) were experimentally determined according with current standards [7]. Table 3 presents the characteristics of the strengthening system applied to each of 9 reinforced tested walls.

This type of strengthening was applied on a set of plane masonry walls built with solid clay bricks and Portland cement mortar. The walls, composed of a single leave, were $90 \mathrm{~cm}$ wide, 13.2 $\mathrm{cm}$ thick and $165 \mathrm{~cm}$ high. Tests on mortar and brick samples yielded a compressive strength of 27.9 and 3.7 MPa respectively. The measured mortar flexural strength was of 1.25 MPa. Tests on composite masonry prisms yielded an average masonry compressive strength of $10.8 \mathrm{MPa}$ and a masonry Young modulus of $780 \mathrm{MPa}$. More information on the mechanical properties of the walls and the type of tests utilized to measure them can be found in $[8,9]$.

Nine strengthened walls were analysed (Fig. 1, left). A summary of the tested walls, with the indication of the materials used in the strengthening and the presence of anchorages is presented in Table 3. In addition, three unreinforced masonry walls were tested for comparison purposes. The unreinforced walls are referred as W\#13, W\#14 and W\#15.

Table 1 - Properties of reinforcing mortars

\begin{tabular}{ccc}
\hline Mortar & $\begin{array}{c}\text { Compressive } \\
\text { strength [MPa] }\end{array}$ & $\begin{array}{c}\text { Flexural strength } \\
\text { [MPa] }\end{array}$ \\
\hline Portland-based & 42.20 & 8.06 \\
Lime-based & 14.53 & 6.57 \\
Pozzolana-based & 34.47 & 9.39 \\
\hline
\end{tabular}

Table 2- Properties of fibre grids

\begin{tabular}{cccc}
\hline Fibre grid & $\begin{array}{c}\text { Tensile strength } \\
{[\mathrm{kN} / \mathrm{m}]}\end{array}$ & $\begin{array}{c}\text { Ultimate } \\
\text { elongation (\%) }\end{array}$ & Grid dimensions \\
\hline Glass & 45 & 3 & $25 \mathrm{~mm} \times 25 \mathrm{~mm}$ \\
Carbon & 160 & 2.1 & $10 \mathrm{~mm} \times 10 \mathrm{~mm}$ \\
\hline
\end{tabular}


Table 3 - Strengthening properties of reinforced tested walls and obtained increase on load bearing capacity

\begin{tabular}{|c|c|c|c|c|c|c|}
\hline Wall \# & $\begin{array}{c}\text { Fibre } \\
\text { grid }\end{array}$ & Mortar & $\begin{array}{l}\text { Fibre } \\
\text { layers }\end{array}$ & Connectors & $\begin{array}{l}N_{\max } \\
{[k N]}\end{array}$ & $\begin{array}{c}\text { Load-bearing } \\
\text { capacity increase } \\
\text { (\%) }\end{array}$ \\
\hline W\#21 & Glass & Portland-based & 1 & 0 & 299.7 & 87 \\
\hline W\#22 & Glass & Portland-based & 1 & 0 & 328.6 & 105 \\
\hline W\#26 & Glass & Portland-based & 2 & 0 & 390.3 & 143 \\
\hline W\#23 & Glass & Lime-based & 1 & 0 & 270.9 & 69 \\
\hline W\#24 & Glass & Lime-based & 1 & 0 & 285.6 & 78 \\
\hline W\#25 & Glass & Lime-based & 2 & 0 & 414.0 & 158 \\
\hline W\#27 & Carbon & $\begin{array}{c}\text { Pozzolana- } \\
\text { based }\end{array}$ & 1 & 0 & 345.7 & 116 \\
\hline W\#28 & Carbon & $\begin{array}{c}\text { Pozzolana- } \\
\text { based }\end{array}$ & 1 & 6 & 313.5 & 96 \\
\hline W\#29 & Carbon & $\begin{array}{l}\text { Pozzolana- } \\
\text { based }\end{array}$ & 1 & 9 & 330.2 & 106 \\
\hline
\end{tabular}

As mentioned, two types of fibre grids were used in the study for strengthening purposes, namely glass fibre and carbon fibre ones. The influence of the grid material was studied by testing walls W\#21, W\#22, W\#23, W\#24 and W\#27. Among these walls, the first four ones were strengthened with glass fibre whereas the last one was strengthened with carbon fibre. To analyse the influence of the amount of fibre two walls were strengthened with two layers of fibre instead of one. Hence, this influence can be analysed by comparing walls W\#21 and W\#22 (one fibre layer) with W\#26 (two fibre layers) and walls W\#23 and W\#24 (one fibre layer) with W\#25 (two fibre layers). In turn, walls W\#21, W\#22 and W\#26 were strengthened with a Portland-based mortar whilst W\#23, W\#24 and W\#25 were strengthened with a lime-based mortar. Although it is the grid what provides the tensile strength, the mortar has a critical role as it transfers the loads from the masonry to the fibre grid. For this reason, three different types of inorganic plaster were used. To analyse the influence of the mortar, walls W\#21 and W\#22 (Portland-based mortar) were compared with walls W\#24 and W\#25 (lime-based mortar) and with wall W\#27 (pozzolana-based mortar). All of them had only one layer of fibre grid.

Knowing that the performance of TRM system depends on the bonding between the masonry and the TRM strengthening, it seemed worth to study the possibility of anchoring the TRM using connectors made of fibres that held the strengthening system from the backside of the wall. To keep the rest of variables out of this particular study, walls W\#27, W\#28 and W\#29 were considered for comparison.

All the walls were tested to failure by applying in-plane gradually increasing vertical compression load. The load was applied with some eccentricity in the direction perpendicular to the mid-surface of the wall, and was uniformly distributed in the wall width. All walls were hinged at their bottom and top edges. Both top and bottom hinges were located so as to produce the same load eccentricity at both ends. Details of the test setup are shown in Fig. 1, right. Prior to the test, the real geometry of the wall, taking into account possible geometrical imperfections and misalignments, was measured with a laser sensor. Two lateral measures, one at each border of the wall, were taken at every 2 masonry rows. The misalignment of the hinges, caused by construction imperfections, was also measured. While the intended eccentricity ad mid height was of $30 \mathrm{~mm}$, the real eccentricity, due to such imperfections, attained values slightly different. 

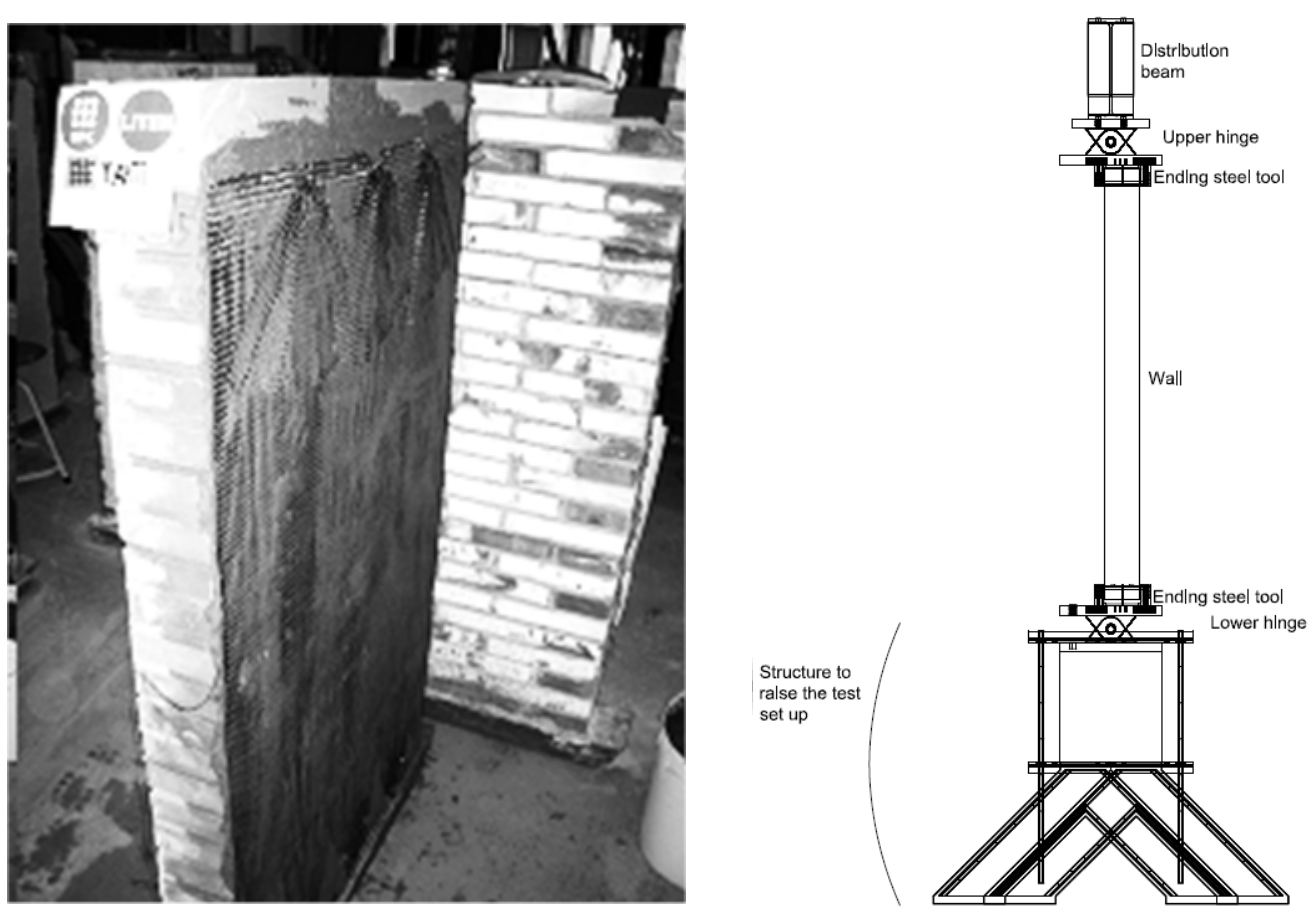

Figure 1. View of reinforced walls (left) and test setup (right).

\section{Experimental results}

The three unreinforced walls tested showed a similar typical buckling failure characterized by the folding of the wall around a hinge (an opened mortar joint) appearing at mid height of the wall. In turn, the reinforced walls showed three different failure modes (Fig. 2). Two TRM strengthened walls (W\#21 and W\#23) also failed by buckling. A single wall (W\#14) collapsed through a mixed mode involving buckling with crushing at the compressed side. The remaining seven TRM strengthened walls (W\#22 and W\#24-W\#29) failed due to crushing in compression near their upper or lower edge. Delamination or debonding between the TRM and the brick wall did not occur in any of the walls tested. Tensile failure of the reinforcement grids was not observed either.

The application of TRM reinforcement reduced in a significant way the scattering on the maximum capacity obtained in the experiments. This scattering was very important in the case of the tested unreinforced walls $[9,10]$.

Fig. 3 shows experimentally obtained curves representing the relationship between the vertical load and the maximum lateral displacement for a selected sample of walls. Fig. 3, a shows the curves obtained for the unreinforced walls, while Fig. 3, b shows the case of walls strengthened with glass fibre and lime based mortar TRM. In these diagrams, the vertical load is measured by a dimensionless parameter $\phi$ defined as

$$
\phi=P_{\max } / P_{u} \text { with } \quad P_{u}=b t f_{c}
$$

where $b$ and $t$ are the width and the thickness of the wall, and $f_{c}$ is the compressive strength of the masonry. The displacement is also described by a dimensionless parameter $h / t$, where $h$ is the displacement. The summary of results, in terms of increase of load bearing capacity allowed by the different strengthening TRM solutions, is presented in table 3. All walls except for W\#14 had the same eccentricity $(30 \mathrm{~mm})$ at their endings. The results of the TRM strengthened walls are compared with the average maximum capacity of the non-strengthened $\mathrm{W \# 13}$ and $\mathrm{W \# 15}$ walls (160.3kN) to evaluate the load-bearing capacity increase. W\#14 is not taken into account for this purpose because it had different load eccentricity. A significant increase of the capacity of the walls, above $100 \%$ in average, was obtained for the mortar and fibre grid types considered. 

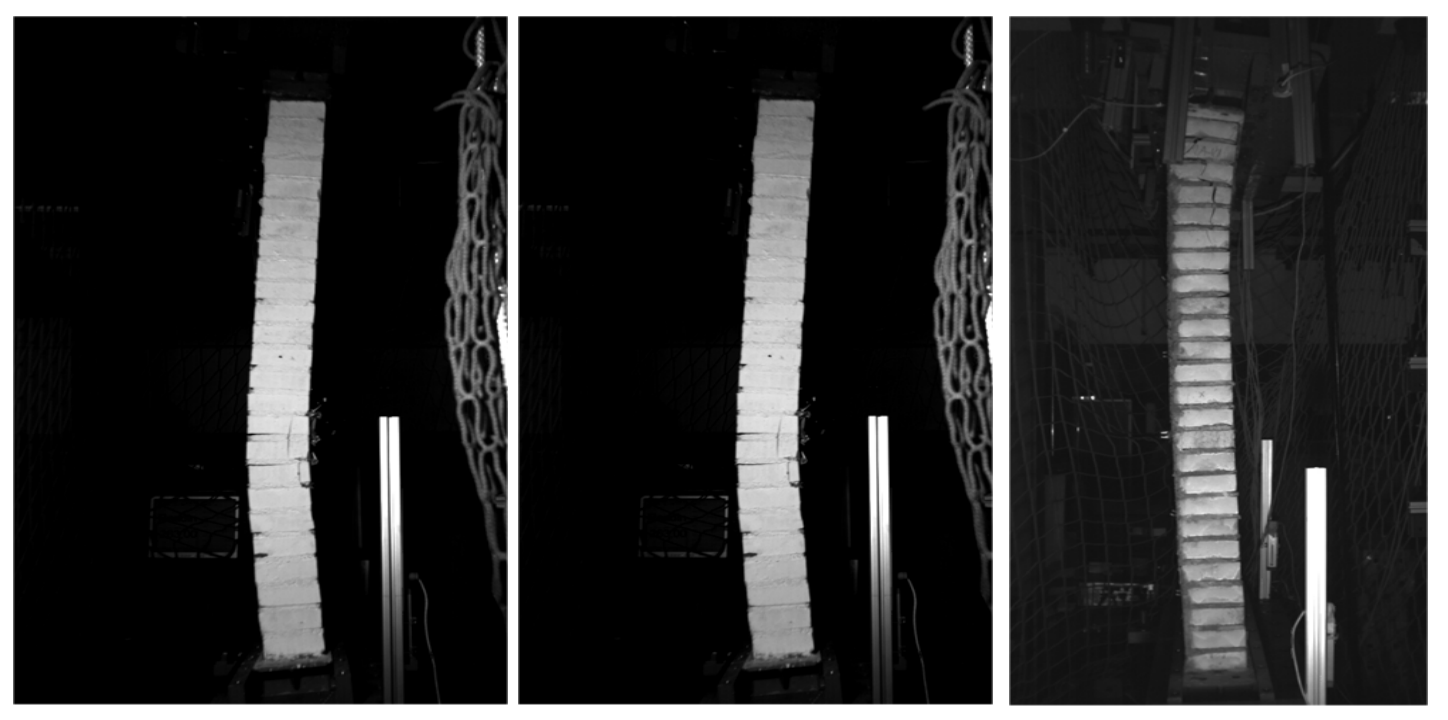

Figure 2. Failure modes shown by TRM strengthened walls: Left: buckling; center: mixed compression and buckling failure; right: compression failure at the top end of wall

(a)

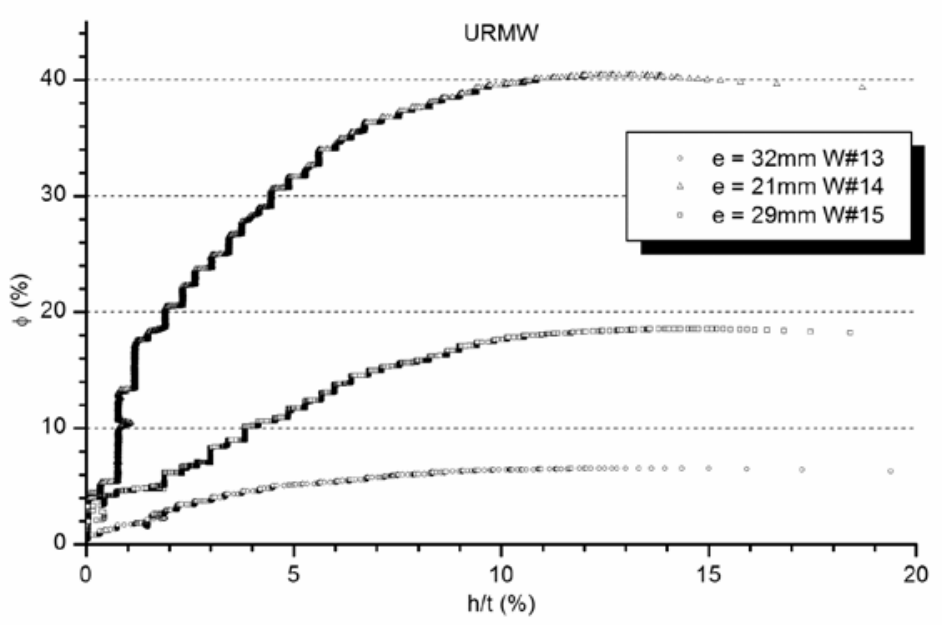

(b)

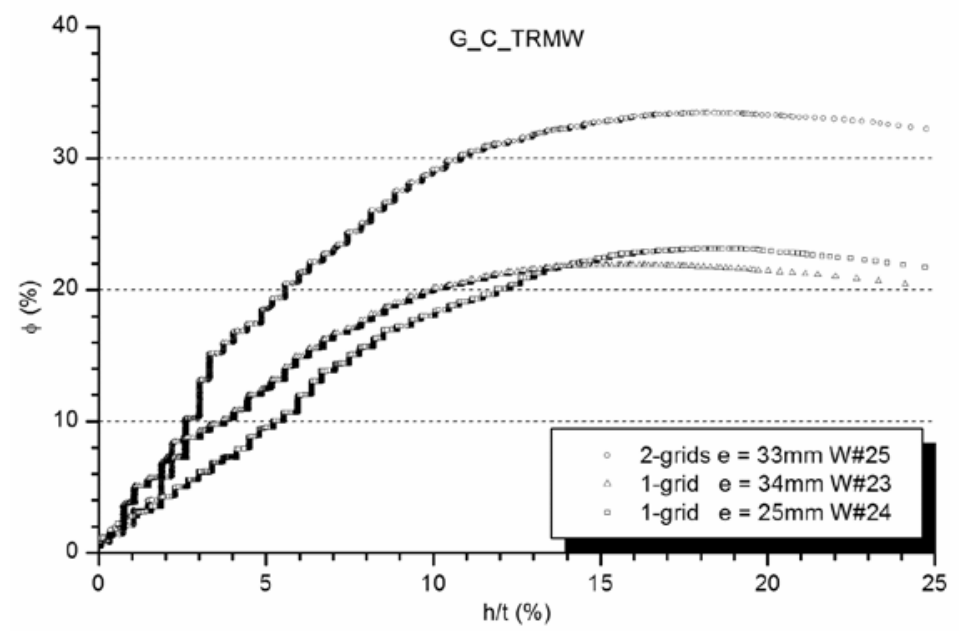

Figure 3. Dimensionless force $(\phi)$ vs dimensionless lateral displacement $(h / t)$ for different applied eccentricities: (a) unreinforced walls; (b) walls reinforced with TRM composed of lime based mortar with glass fibre grid. The legend indicates the eccentricity at mid-height of the wall. 
For a single grid layer, Portland-based mortar combined with glass grids fiber and pozzolana-based mortar with carbon fiber grids produced a similar capacity increase of about $100 \%$. Lime-based mortar combined with glass fiber produced a lesser, although still meaningful increase about $70 \%$. It was observed that the number of fibre grids also has significant influence on resulting capacity. Providing two grid layers to the TRM caused an increase about $150 \%$ with respect to the capacity of the unreinforced walls. Finally, placing connectors did not significantly influence on the capacity of the walls.

Regarding the efficiency of the different TRM solutions tried, it can be noted that applying a single glass fibre grid (comparable to the used ones) provides a close to optimal strengthening solution. This conclusion, which is at least applicable to the simply supported configuration and the tested geometry and materials, is based on the fact that most of the walls failed because of the attainment of the masonry ultimate strain in compression, or in a condition very close to it. Therefore, improving the TRM tensile capacity with the application of more than one glass fibre grid only causes a moderate increase of the load bearing capacity of the walls. For the same reasons, no perceptible advantage was noted when carbon fibre grids were used instead of glass fibre ones.

The mechanical properties of the mortar had also some influence on the strengthening capacity of the TRM arrangements. Specifically, the use of lime mortar, with compressive and flexural strength smaller than those of the other two mortars utilized, provided a smaller increase of capacity. However, and as mentioned, the increase of capacity allowed by the lime mortar TRM was still significant and attained about a $70 \%$ of the initial wall capacity. Therefore, lime-based TRM can be presented as a viable strengthening solution able to provide a satisfactory enhancement of the strength capacity of load bearing walls.

\section{Analytical method}

A simplified calculation method based on the equilibrium and strain compatibility conditions is proposed to assess the response of TRM strengthened masonry walls. Based on the experimental results, it is supposed that the strengthening system prevents the pure buckling failure and limits the second order effects, turning the problem into a sectional strength analysis. Two failure modes are considered, corresponding to the failure of the wall in compression, or to the failure of the fibre grid in tension. A linear strain distribution in the wall's thickness is assumed. Stresses in compressed masonry are modeled as a plastic rectangular block, for failure due to masonry, and as a triangular diagram for failure of the fibre grid in tension. In turn, the fibre grid is modelled as an elastic linear material up to the attainment of its tensile strength. The calculation procedure consists of obtaining the axial $(N)$ - bending $(M)$ interaction curve determined by the two failure modes.

The comparison of the experimental and analytically predicted load bearing capacities is presented in table 4 . The table compares the value of the moment resisted $(M)$ for the applied normal force $(N)$. The comparison is done in terms of normalized normal forces and moments, respectively calculated as $N / P_{u}$ and $8 M /\left(P_{u} t\right)$. In general, the method predicts in an acceptable way the experimental values.

\section{Conclusions}

An experimental research on real-size TRM strengthened brick masonry walls under eccentric compressive load has been presented. The research included the testing to failure of masonry walls strengthened with different types of mortar (Portland-, lime- and pozzolana- based) and two types of grids (glass fiber and carbon fiber ones). The strengthened walls showed a notable increase, about $100 \%$ in average, of their load bearing capacity. Moreover, all mortars reached the necessary bonding strength to assure the bonding of the TRM to the masonry throughout the loading process. In fact, no delamination or debonding was observed between the TRM strengthening and the wall surface in all tested walls. Therefore, connectors seem unnecessary and actually did not contribute with any noticeable increase of capacity in the walls that were provided with them. 
The failure was due, in most cases, to masonry crushing. Buckling failure, which is the common failure of unreinforced masonry walls, was only observed in two TRM reinforced walls. In general, it can be said that the TRM reinforcement highly limits or avoids the possibility of a pure buckling failure.

A simple analytical method has been proposed for the calculation of the axial-moment interaction curve of TRM reinforced brick masonry walls. The method is based on common assumptions adopted for the analysis of reinforced concrete flexural members. The analytical procedure has provided predictions in acceptable agreement with the experimental results.

Table 4. Results of the analytical method and comparison with analytical formulation

\begin{tabular}{ccccc}
\hline Wall & Grid (layers) & $\boldsymbol{N}^{\text {exp }} / \boldsymbol{P}_{u}$ & $\boldsymbol{M}^{\text {exp }} /\left(\boldsymbol{P}_{u} \mathbf{t} / \mathbf{8}\right)$ & $\begin{array}{c}\text { analytical } \\
\boldsymbol{M}^{\text {analytic }} /\left(\boldsymbol{P}_{u} \boldsymbol{t} / \mathbf{8}\right)\end{array}$ \\
\hline W\#21 & & 0.224 & 0.648 & 0.765 \\
W\#22 & \multirow{2}{*}{ Glass (1) } & 0.245 & 0.828 & 0.841 \\
W\#23 & & 0.202 & 0.618 & 0.725 \\
W\#24 & & 0.213 & 0.667 & 0.746 \\
\hline W\#25 & \multirow{2}{*}{ Glass (2) } & 0.295 & 0.787 & 0.906 \\
W\#26 & & 0.312 & 1.027 & 0.926 \\
\hline W\#27 & & 0.250 & 0.708 & 0.826 \\
W\#28 & \multirow{2}{*}{ Carbon (1) } & 0.237 & 0.575 & 0.806 \\
W\#29 & & 0.262 & 0.865 & 0.844 \\
\hline
\end{tabular}

\section{Acknowledgements}

This study has been partially carried out within the project "Uso de nuevos materiales composites para el refuerzo y rehabilitación de estructuras de edificación y obra civil con criterios de sostenibilidad TERREME', funded by the Spanish Ministry of Economics and Competitiveness, and Project BIA 2009-13233, funded by the DGE of the Spanish Ministry of Science and Innovation, whose assistance is gratefully acknowledged. The support of Ibermapei, S.A. and Ruredil, SpA is also acknowledged.

\section{References}

[1] Papanicolaou CG, Triantafillou TC, Papathanasiou M, Karlos K. Textile reinforced mortar (TRM) versus FRP as strengthening material of URM walls: out-of-plane cyclic loading. Mater Struct. 41 (2007) 143-57.

[2] Hamed E, Rabinovitch O. Lateral out-of-plane strengthening of masonry walls with composite materials. J Compos Contr. 14 (2010); 376.

[3] Baratta A, Corbi O. Stress analysis of masonry vaults and static efficacy of FRP repairs. Int J Solids Struct. 44 (2007) 8028-56.

[4] Delorenzis L, Dimitri R, Lategola a. Reduction of the lateral thrust of masonry arches and vaults with FRP composites. Constr Build Mater. 21 (2007) 1415-30.

[5] Foraboschi P. Strengthening of Masonry Arches with Fiber-Reinforced Polymer Strips. J Compos Contr. 8 (2004) 191.

[6] Shrive N. The use of fibre reinforced polymers to improve seismic resistance of masonry. Constr Build Mater. 20 (2006) 269-77. 
[7] 83 CAC. UNE-EN 1015-11:2000/A1:2007. Métodos de ensayo de los morteros para albañilería. Parte 11: Determinación de la resistencia a flexión y a compresión del mortero endurecido. AENOR, Madrid, 2007.

[8] Bernat, E., Gil, L., Roca, P., Escrig, C., Experimental and analytical study of TRM strengthened brickwork walls under eccentric compressive loading. Construction and Building Materials 44, (2013) 35-47

[9] Bernat, E. Analysis of unreinforced and TRM-strengthened brick masonry walls subjected to eccentric axial load. Ph. D. dissertation, Universitat Politècnica de Catalunya, Barcelona, 2013.

[10] Bernat, E., Gil, L., Roca, P., Sandoval, C., Experimental and numerical analysis of bendingbuckling mixed failure of brickwork walls. Construction and building materials 43, 2013, 1-13. 